\title{
Primary Muscular Cystic Echinococcosis: A Rare Case Report
}

\author{
Shahbaz Habib Faridi*, Rahil Rafiq and Syed Amjad Ali Rizvi \\ Department of Surgery, J N Medical College, AMU, India
}

Submission: February 01, 2017; Published: February 09, 2017

*Corresponding author: Shahbaz Habib Faridi, Assistant Professor, Department of Surgery, JN Medical College, AMU, Aligarh, PIN- 202002, India, Tel: 7417775996; Email: shahbazfaridi@yahoo.com; rhlrfq@gmail.com

\begin{abstract}
Hydatid cyst primarily affects organs like liver and lungs. Intramuscular hydatid cysts are very rare probably because of hostile environment within the muscles. Intramuscular hydatid cysts if present are mostly secondary, resulting from the spread of cysts from other areas either spontaneously or during operations. We present an unusual case of a primary intramuscular hydatid cyst found in the right thigh of a 36-year-old man, presenting as an enlarging mass. Magnetic resonance imaging examinations revealed a multilocular intramuscular cyst in the anterior aspect of right thigh with close relation to neurovascular bundle. The entire cyst was removed surgically and histopathological examinations confirmed the diagnosis of muscular hydatidosis. In highly endemic regions, undiagnosed mass at any site should be considered a hydatid cyst until proven otherwise.
\end{abstract}

Keywords: Primary hydatidosis of muscles; Femoral hydatid cyst; Intramuscular hydatid cyst; Muscular echinococcosis

\section{Introduction}

Hydatid is a Greek word meaning "watery cyst". Echinococcosis, also called Hydatid disease is a parasitic disease caused by the larval stage of tapeworm Echinococcus (E. granulosus, and less commonly E. multilocularis) [1]. Humans are accidental host and get infected through contact with the definitive host or by the ingestion of food or water containing the larvae of Echinococcus. The commonest Echinococcus species affecting man is E. granulosus, followed by less commoner E. multilocularis and $E$. vogeli. The disease is prevalent in the Mediterranean region, the Middle East, Central Asia, East Africa, South America, Australia and New Zealand [2].

The parasite's life cycle involves a definitive host, usually dog or any another carnivore and an intermediate host, usually sheep or any other herbivore. The adult parasite lives in the proximal small bowel of the definitive host and sheds its eggs through host's feces into the environment where intermediate host gets infected when grazing on contaminated ground. After ingestion of the egg, the embryo (oncosphere) hatches, penetrates the intestinal mucosa, enters into the host's circulatory system and develops into metacestode when reaching a suitable anatomical site after (while evading the host's immune response). This stage is characterized by a cystic lesion ('hydatid', 'hydatid cyst'), which expands by concentric enlargement (approximately around 1-5 $\mathrm{cm}$ per year in diameter) within the affected organ and contains protoscolices. The cycle is completed when the definitive host feeds on infected organs of the intermediate host [3].

When humans ingest the eggs of the tapeworm, embryos emerge from the eggs and penetrate the intestinal mucosa. From there the embryos are transported via the blood to various organs and get lodged in organs like liver (65-75\% of all cases) and lungs (25 - 30\% of all cases). In children the most common organ being lungs followed by liver. Other organs such as the spleen, heart and brain are affected rarely [4,5]. Bone and soft-tissue hydatid disease are rare form of presentation of hydatid disease and account for around 1 - 5\% of all cases. The environment in muscles is toxic to the establishment and growth of the cestode because of the increased concentration of the lactic acid and the movement of the muscles. Most of the muscular hydatid disease are secondary to visceral involvement and primary muscular hydatid diseases is even rarer, with most common sites being the neck, trunk and roots of the limbs [6,7]. We report a rare case of a primary intramuscular hydatid cyst of femoral muscles in a man who presented as a mass in the right thigh, making diagnosis very difficult.

\section{Case Report}

A 36-year old man was admitted to our hospital with presenting complaint of painless enlarging swelling in his right 
thigh which he had noticed from 2 years. He had no history of trauma, surgery or any other diseases. Physical examination revealed a non-tender mass measuring $17.0 \times 14.0 \mathrm{~cm}$ in his right thigh, located $4 \mathrm{~cm}$ below mid-point of right inguinal ligament. There was no redness over the skin or any lymphadenopathy (Figure 1). He had no restriction of movement at hip and knee joints, and he also had equal peripheral pulses in both lower limbs. Blood investigations were normal. Plain X-rays of the right thigh showed no bony involvement. Magnetic resonance imaging (MRI) right thigh revealed a heterogeneously enhancing cystic lesion with multiple variable sized cystic lesions within it involving the right vastus intermedius and vastus medialis with close relation to neurovascular bundle on the medial side. Findings were suggestive of hydatid cyst (Figure 2).

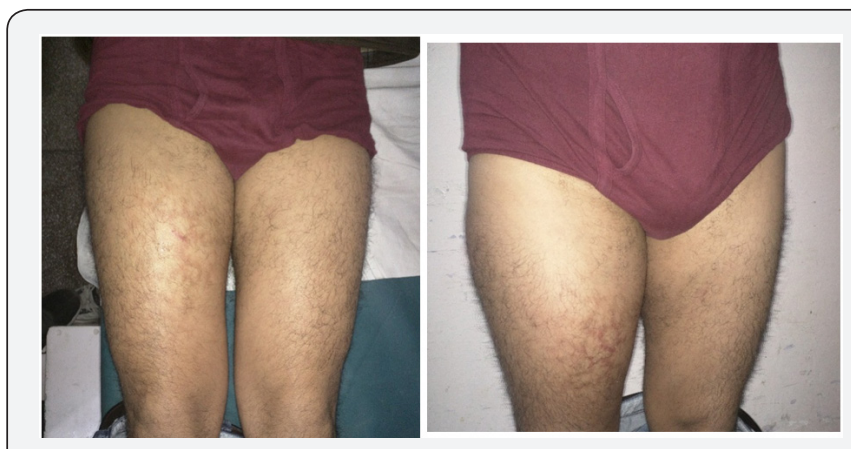

Figure 1: There was no redness over the skin or any lymphadenopathy.

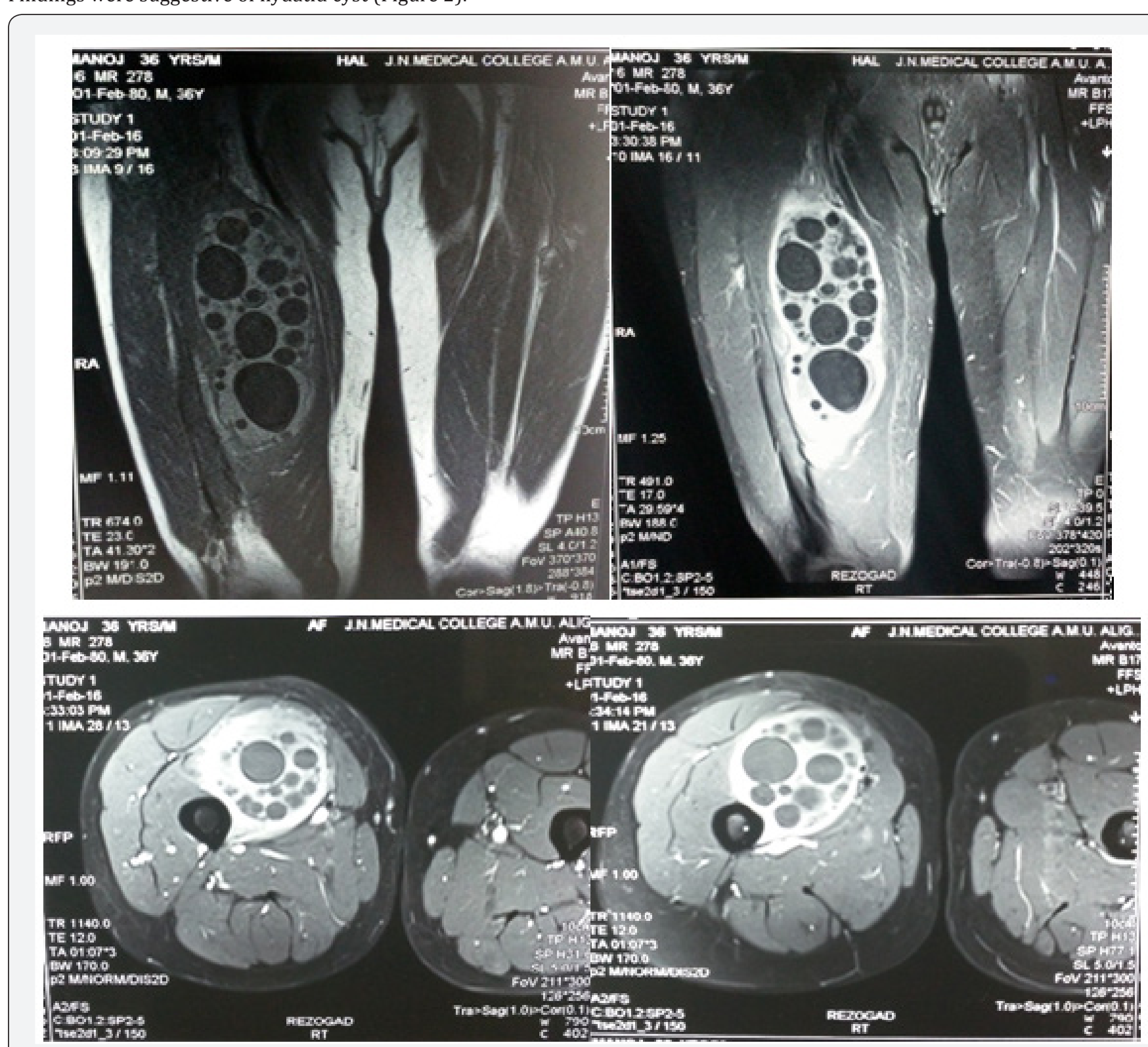

Figure 2: Findings were suggestive of hydatid cyst. 


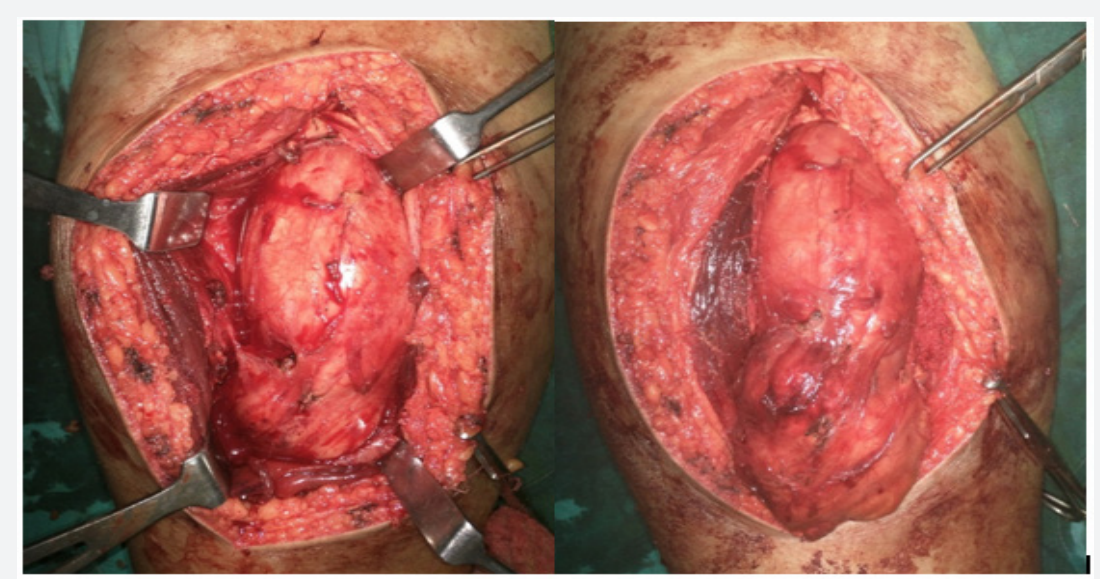

Figure 3: The entire cyst along with pericyst was carefully dissected free from its surrounding muscles and bone posteriorly, taking great care of neurovascular bundle on the medial side which was in close relation.
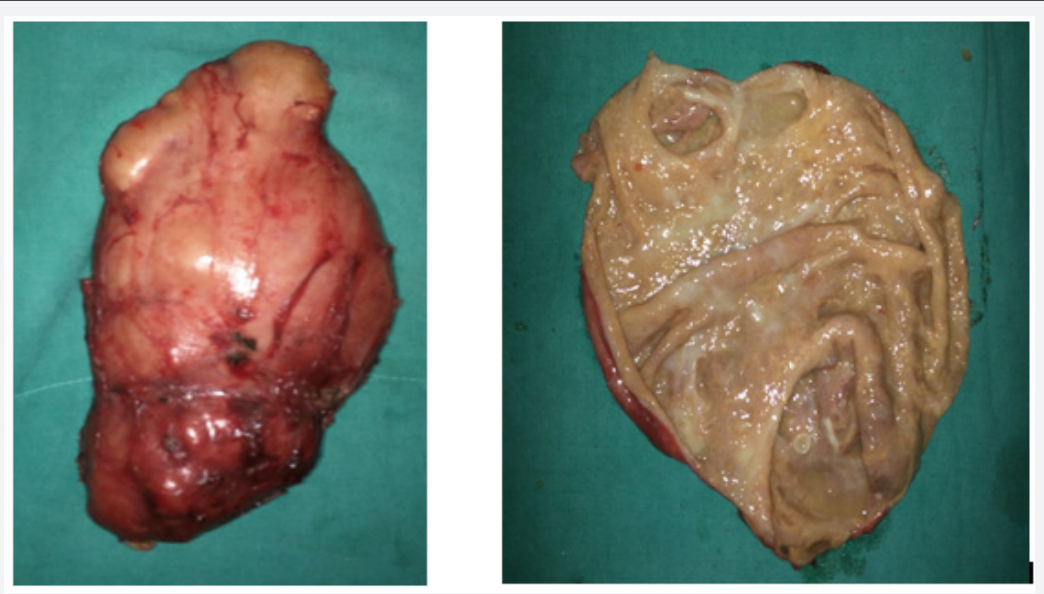

Figure 4: Histopathological examinations confirmed the diagnosis of a hydatid cyst.

Careful clinical examination, plain chest X-ray and ultrasonography of abdomen was done to rule out any other lesion in the body. Patient was prescribed albendazole (15mg/ $\mathrm{kg} /$ day orally in two divided doses) for 3 weeks and planned for enucleation under spinal anesthesia. The entire cyst along with pericyst was carefully dissected free from its surrounding muscles and bone posteriorly, taking great care of neurovascular bundle on the medial sides which were in close relation (Figure 3 ). The cyst was then taken out while preventing any spillage from cyst. Histopathological examinations confirmed the diagnosis of a hydatid cyst (Figure 4). In the immediate postoperative period, patient had no neurovascular deficit in his right lower limb and his recovery was uneventful. He was started on albendazole (15mg/kg/day orally in two divided doses) again which is to be continued for 5 months.

\section{Discussion}

Hydatid cysts in muscles are usually secondary because of spread from other areas, either spontaneously or during surgery for Hydatidosis in other regions of the body [8]. Primary intramuscular hydatid cyst is rare because the growth of cysts within the muscle is hindered by the contraction and relaxation of the muscle and by the high local concentration of the lactic acid in the muscle. Parasitic cysts most commonly grow around the muscles of the neck, trunk and roots of the limbs, probably because of less muscular activity and more vascular supply in these areas. They develop very slowly and produce symptoms mostly related to pressure exerted by the cyst on the surrounding tissues $[6,9,10]$. The more common primary locations like liver and lungs must be excluded by clinical and radiological examination of the patient. Various serological tests like ELISA, Casoni`s test are available for the diagnosis of Hydatidosis. Immunoelectrophoresis is the most specific method till date. Ultrasonography is helpful in determining the cystic nature of the muscular mass, while CT and MRI findings show the location, size, appearance and relation of the cyst to other structures. In muscles the hydatid cyst is typically a big unilocular cyst, often named as mother cyst, which usually contains multiple smaller secondary cysts, often named as daughter cysts $[7,11,12]$. 
It is very important to identify or suspect the presence of a hydatid cyst before surgery, because inadvertent biopsy of the cyst has to be avoided, and the spillage of the contents from improper handling during surgical resection of the cyst has to be prevented. Rupture of the cyst contents can enable secondary cysts to occur. Operative field must be washed with scolicidal agents like hypertonic saline to prevent any recurrence. The treatment of choice for muscular hydatid disease is complete surgical excision of the cyst (or drainage if the cyst is in a difficult location) followed by thorough irrigation of the surrounding tissue with scolicidal agents to prevent recurrence. Systemic anti-parasitic drugs like albendazole are advised peri-operatively and continued post-operatively for 5-6 months. The patient is followed for long-term to check for recurrence.

\section{Conclusion}

Hydatid cysts in muscle are a very rare form of presentation of Echinococcosis. However in highly endemic regions, undiagnosed mass at any site should be considered a hydatid cyst until proven otherwise.

\section{Patient Permission}

Written permission/consent was taken for publication of images and case report.

\section{References}

1. Arif S, Zaheer S (2009) Intradural extramedullary primary hydatid cyst of the spine in a child: a very rare presentation. Eur Spine J 18(2): 179182.
2. M Necmettin Pamir, Koray O zduman, Ilhan Elmaci (2002) Spinal hydatid disease. Spinal Cord 40: 153-160.

3. Schantz PMK, P Brunetti (2006) Echinococcosis. In: Guerrant RLW, D.H.;Weller,P.F., editor. Tropical Infectious Diseases: Principles, Pathogens \& Practice. ( $\left.2^{\text {nd }} e d n\right)$, Churchill Livingstone (Elsevier), Philadelphia, USA, pp. 1304-1325.

4. Ok E, Sözüer EM (2000) Solitary subcutaneous hydatid cyst: a case report. Am J Trop Med Hyg 62(5): 583-584.

5. Yaghan RJ (1999) Hydatid disease of the breast: a case report and literature review. Am J Trop Med Hyg 61(5): 714-715.

6. Yörükoğlu Y, Zengin M, Dolgun A, Nazliel K, Salman E, et al. (1993) Primary muscular hydatid cyst causing arterial insufficiency: case report and literature review. Angiology 44(5): 399-401.

7. García-Díez AI, Ros Mendoza LH, Villacampa VM, Cózar M, Fuertes MI (2000) MRI evaluation of soft tissue hydatid disease. Eur Radiol 10(3): 462-466.

8. Dudkiewicz I, Salai M, Apter S (1999) Hydatid cyst presenting as a softtissue thigh mass in a child. Arch Orthop Trauma Surg 119(7-8): 474475 .

9. Lamine A, Fikry T, Zryouil B (1993) L'hydatidose primitive des muscles peripheriques a propos de 7 cas (in French). Acta Orthop Belg 59(2): 184-188.

10. Freedman AN (1974) Muscular hydatid disease: report of a case and review of the literature. Can J Surg 17(4): 232-234.

11. Martin J, Marco V, Zidan A, Marco C (1993) Hydatid disease of the soft tissues of the lower limb: findings in three cases. Skeletal Radiol 22(7): 511-514.

12. von Sinner WN (1991) New diagnostic signs in hydatid disease: radiography, ultrasound, CT and MRI correlated to pathology. Eur J Radiol 12(2): 150-159.
Your next submission with Juniper Publishers will reach you the below assets

- Quality Editorial service

- Swift Peer Review

- Reprints availability

- E-prints Service

- Manuscript Podcast for convenient understanding

- Global attainment for your research

- Manuscript accessibility in different formats ( Pdf, E-pub, Full Text, Audio)

- Unceasing customer service

Track the below URL for one-step submission https://juniperpublishers.com/online-submission.php 